\title{
Dealing with democracy
}

The drive for greater public participation in the regulation and politics of technologies is both necessary and irreversible. But proposals to extend it into the selection of publicly funded research contain dangers to science and society.

T he increasing involvement of the public in the policy-making and regulation of science and technology is to be welcomed. As a recent forum of supportive discussions describes (see Science and Public Policy 30, 146-225; 2003), governments, parliaments and other public organizations in France, Germany and Britain are taking significant steps in this direction, no doubt partly inspired by models such as consensus conferences pioneered in Scandinavia. The European Commission has published a White Paper extolling the virtues and processes of public participation, and is implementing it in its Sixth Framework research programme.

As the forum also makes clear, this is in increasingly sharp contrast to the United States where, despite enviable traditions of stakeholder involvement, the Bush administration is moving against public access to decision-making and towards the biasing of advisory bodies to suit its own agendas. Advocates of public participation, such as the Loka Institute, find themselves further out in the wilderness than they have been for a long while.

The European shift towards broad public participation is an appropriate move against the idea that experts always know best. That idea underpins the 'deficit model' — the label given by professionals in the business of public understanding and consultation to the mistaken belief that the public's mistrust of science and technology can be removed simply by explaining scientific concepts, processes and facts.

These same professionals are all too quick to regurgitate the cliché that the deficit model is dead. Indeed it is, and few scientists who have any experience of societal distrust would nowadays maintain that scientific reassurance and knowledge are all that are needed to remove it. But even so, crippling deficits of knowledge and understanding remain, between scientific disciplines and, in both directions, between science and its stakeholders. The goal of increased public accountability and participation serves only to highlight such deficits. This represents a major but unavoidable challenge for governments, who are ultimately responsible for ensuring that citizens can obtain timely and comprehensible information about politically controversial science and technology from trustworthy sources.

\section{More involvement}

Expertise is not confined to researchers, however. Whatever their stance, lobbyists, patients' groups and environmental stakeholders often take the time to explore and question the literature in depth. And there is no inevitable polarization between researchers and the public. Rather, polarization can reflect shared attitudes towards technologies such as embryonic stem cells, reproductive cloning and nuclear fission reactors, or towards burdens of proof about the impact of technologies in decisions about regulation.

Despite the evident progress in formalized public participation and discussion, there are those who say that this is not enough, and that the selection of science for funding should also be subject to public involvement. In their contribution to the forum, policy researchers Reiner Grundmann and Nico Stehr propose that sciencerelated politics should be reinvented from the ground up. This, they say, is because the power of science to alter nature has reached such a state that society needs to have a much more fundamental place in considering its support. Sue Mayer, director of the lobby group Genewatch UK, takes a similar line. Inadequate representation of the wider public in the funding and intellectual-property systems, she says, leaves them with insufficient scope to "influence the trajectory or accessibility of scientific information".

Many will perceive proposals for further democratic involvement as an anti-science Trojan horse standing outside science's citadel. The proposals would certainly need critical scrutiny, as they bear all the hallmarks of advocacy rather than analysis. They understate the existing means by which scientific communities are subject to democratic discussions and regulation, and oversimplify episodes that they invoke as symptoms of scientists' resistance to restraint. They ignore the subtleties of the way in which fundamental science is unpredictable, unavoidably sets its own agendas, and has an inherent timescale, both in its community structure and its execution, that is ill matched to the short-term perceptions of public opinion. With such shortcomings, they carry dangers both for science and for society.

But the proposals have virtues too. There is a strong case for funding agencies to include people who are particularly motivated to encourage research into controversial science and its applications on a broader basis than the pursuit of national wealth or power, or'sweet technology' for its own sake.

\section{A balanced approach}

In short, science's structures need to avoid procedural savagery equivalent to the destruction of trials of genetically modified (GM) crops and physical attacks on animal researchers, while taking democratic steps that, by increasing society's trust in the pursuit of scientific insights, lessen the likelihood of such vandalism. This week sees the publication of the results of an unprecedented public consultation about GM crops, instigated by the UK government (see page 331). There will no doubt be headlines about the British public's well-known scepticism of the technology. But attention also needs to be paid to the strongly held view emerging from the survey that more research on GM crops needs to be done.

Proposals for more democracy also deserve critical scrutiny with regard to the process. There has been much public participation over the years in many countries, and remarkably little analysis of its effectiveness and participants' experiences. For example, too many citizen's juries seem to align themselves with the positions of those who commissioned them. Glib advocacy for more and deeper 'democratization' is no longer good enough. Critical evaluation is needed of the successes and dangers in the process.

Are we all experts now? Is this the century of the informed, competent, and ever more emancipated global expert-citizen? To the extent that, thanks to the Internet and public consultations, the answers to these questions are increasingly affirmative, the scientific community needs to adapt to the public's need for accountability and trust. To the extent that the answers to both are still negative, science needs to defend itself against threats from fundamentalism and ignorance. This balance between adaptation and resistance will challenge scientific communities for the foreseeable future. But both will be required. 